\title{
Research on the Dynamic Compressive Deformation Behavior of 3D-Printed Ti6Al4V
}

\author{
Bo Pu, Wenbin Li *, Qing Zhang, Yu Zheng and Xiaoming Wang
}

Citation: Pu, B.; Li, W.; Zhang, Q.; Zheng, Y.; Wang, X. Research on the Dynamic Compressive Deformation Behavior of 3D-Printed Ti6Al4V. Metals 2021, 11, 1327. https:// doi.org/10.3390/met11081327

Academic Editor: Patrick Pradel

Received: 19 July 2021

Accepted: 20 August 2021

Published: 23 August 2021

Publisher's Note: MDPI stays neutral with regard to jurisdictional claims in published maps and institutional affiliations.

Copyright: (c) 2021 by the authors. Licensee MDPI, Basel, Switzerland. This article is an open access article distributed under the terms and conditions of the Creative Commons Attribution (CC BY) license (https:// creativecommons.org/licenses/by/ $4.0 /)$.
Ministerial Key Laboratory of ZNDY, Nanjing University of Science and Technology, Nanjing 210094, China; 316101002454@njust.edu.cn (B.P.); qingzhang827@163.com (Q.Z.); zhengyu@njust.edu.cn (Y.Z.); 202xm@163.com (X.W.)

* Correspondence: lwb2000cn@njust.edu.cn

\begin{abstract}
In this paper, the plastic flow and fracture behavior of 3D-printed Ti6Al4V (TC-4) alloy under different temperatures $(289-1073 \mathrm{~K})$ and strain rates $\left(0.1-4100 \mathrm{~s}^{-1}\right)$ were studied by using the MTS comprehensive experimental machine (MTS) and split Hopkinson pressure bar (SHPB) equipment. The patterns of the influence of temperature and strain rate on the plastic flow behavior of 3D-printed materials in different printing directions were analyzed and compared with those of the traditional TC-4. Based on the experimental data, the modified Johnson-Cook (J-C) constitutive model of 3D-printed TC-4 alloy was established, and the plastic deformation behavior of the material driven by detonation was studied by $\mathrm{X}$-ray photography. The research results showed that under static loading conditions, the strength of the material (AM-P-TC-4) along the printing direction was much higher than the strength of the material perpendicular to the printing direction (AM-T-TC-4). However, there was no difference in material strength for different directions under dynamic loading. Second, under the same deformation conditions, the strength of the 3D-printed TC-4 alloy was considerably higher than that of the traditional TC-4 alloy, but adiabatic shear fracture could be more easily induced under dynamic compressive deformation conditions for the 3D-printed TC-4 alloy, and its fracture strain was substantially less than that of TC-4 alloys. The modified J-C constitutive model established in this paper could better describe the plastic flow behavior of the AM-P-TC-4 alloy under high temperature and high-strain rate deformation conditions.
\end{abstract}

Keywords: Ti6Al4V; additive manufacturing; dynamic mechanical properties; high temperature; high strain rate

\section{Introduction}

The titanium alloy Ti6Al4V, a typical $\alpha+\beta$ two-phase material, has several advantages, such as low density, high elastic modulus, high strength, and good corrosion resistance and processing performance, and it has been widely used in aerospace, vehicle engineering, shipbuilding, and defense [1,2]. Traditional Ti6Al4V (TC-4) alloy parts are usually prepared in the production process of forging and casting in combination with turning. However, for some large and complex components, the subtractive preparation process has issues of high costs, complex processes, low material utilization, and long processing cycle, which severely hinders the further application of this material in the industrial field. Additive manufacturing is a new industrial technology that emerged in the early 21th century. It mainly involves the use of laser technology to accumulate the spread powder materials layer by layer through computer control to obtain three-dimensional physical products [3]. The processing method adopted by 3D-printing technology is opposite to the traditional subtractive technology, and it can effectively solve production process problems in the manufacturing and preparation of some difficult-to-process, precious-metal and complex parts.

Ti-6Al-4V is a mature titanium alloy material widely used in various industrial fields. Numerous studies have been conducted on the mechanical properties of traditional Ti- 
6Al-4V materials [4-8]. Nitin [4] studied the effect of heat treatment on the mechanical properties of Ti-6Al-4V at low strain rates. Lee [7] studied the plastic flow and fracture behavior of Ti-6Al-4V under dynamic deformation conditions using the split-Hopkinson pressure bar (SHPB) method. Thus far, there have been few studies on the mechanical properties of 3D-printed Ti-6Al-4V under dynamic deformation conditions. More studies have focused mainly on the effects of void defects and complex structures within the material on the macro-mechanical behavior of 3D-printed Ti-6Al-4V and the influence of the printing process on the static strength of the material [9-18]. Refael et al. [12,14] studied the effect of holes on the dynamic mechanical properties of 3D-printed Ti6Al4V alloy specimens through dynamic compression and tensile tests. Xiao et al. [16-18] used 3D-printing technology to prepare an open-cell rhombic dodecahedron Ti-6Al-4V lattice structure and studied the macro-mechanical response of this structure under dynamic and static compressive deformation conditions through a series of mechanical experiments. Numerous research data have shown that the strength of 3D-printed Ti-6Al-4V alloy is considerably higher than that of Ti-6Al-4V materials prepared by the traditional technology, but many voids and defects exist inside the 3D-printed Ti-6Al-4V alloy that have negative effects on the mechanical properties of the alloy.

To systematically study and predict the deformation behavior of 3D-printed Ti-6Al$4 \mathrm{~V}$ materials under high-speed-impact conditions, selective laser melting 3D-printing technology was used in this study to prepare 3D-printed Ti-6Al-4V alloy plates, and the wire electrical discharge machining (WEDM) process was used to cut and obtain mechanical specimens from the longitudinal printing direction (AM-P-TC-4) and transverse printing direction (AM-T-TC-4) of the material. The mechanical response and fracture behavior of the 3D-printed TC-4 material in different printing directions were studied through quasi-static and dynamic compression tests under deformation at different temperatures (289-1073 K) and strain rates $\left(0.1-4100 \mathrm{~s}^{-1}\right)$, and the results were compared with those of the Ti-6Al-4V alloy (TC-4) prepared via the traditional process. Moreover, based on experimental data, a modified Johnson-Cook (J-C) constitutive model that could predict the dynamic plastic deformation behavior of AM-P-TC-4 and TC-4 was established. Finally, a comparative study of the detonation-driving plastic deformation behaviors of AM-P-TC-4 and TC-4 was performed using a shaped-charge jet warhead.

\section{Materials and Test Methods}

\subsection{Materials}

TC-4 (Ti-6Al-4V) produced by the Northwest Institute for Nonferrous Metal Research was used as the traditional forged titanium alloy, and the additively manufactured titanium alloy was prepared based on the selective laser melting (SLM) process. The chemical compositions of the two materials are presented in Table 1. The TC-4 spherical powder for additive manufacturing had a particle size of $15-53 \mu \mathrm{m}$.

Table 1. Chemical compositions of TC-4 and AM-TC-4.

\begin{tabular}{cccccc}
\hline \multirow{2}{*}{ Material } & \multicolumn{5}{c}{ Composition (wt.\%) } \\
\cline { 2 - 6 } & $\mathbf{A l}$ & $\mathbf{V}$ & $\mathbf{O}$ & $\mathbf{F e}$ & $\mathbf{T i}$ \\
\hline TC-4 & 6.30 & 4.10 & $<0.14$ & $<0.14$ & Balance \\
AM-TC-4 & 6.13 & 4.00 & $<0.15$ & $<0.25$ & Balance \\
\hline
\end{tabular}

The SLM equipment was developed in-house as shown in Figure 1. A fiber laser with its wavelength at $1070 \mathrm{~nm}$ and a maximum power of $500 \mathrm{~W}$ was used. The laser spot size on the surface of the powder bed is about $100 \mu \mathrm{m}$. To prevent the metal powder from being oxidized during the manufacturing process, argon was used as the protective gas, and the oxygen content was constantly maintained at below $100 \mathrm{ppm}$ (parts per million) during the manufacturing process. A laser power of $340 \mathrm{~W}$, scan speed of $1250 \mathrm{~mm} / \mathrm{s}$, and layer thickness of $60 \mu \mathrm{m}$ were used to produce the samples. The powder bed was heated to 
a temperature of $100{ }^{\circ} \mathrm{C}$ to reduce the thermal deformation of the samples. The process parameters are presented in Table 2 , and the dimensions of the additively manufactured sample were $40 \mathrm{~mm} \times 40 \mathrm{~mm} \times 4 \mathrm{~mm}$. After the additive manufacturing was complete, the sample was subjected to annealing heat treatment (the environmental temperature was raised to $800^{\circ} \mathrm{C}$ for $60 \mathrm{~min}$ and held for $2 \mathrm{~h}$, followed by air cooling). The final sample after machining is shown in Figure 2. The Leica MC170HD inverted-phase metallographic microscope (Leica, Berlin, Germany) was used to observe the microstructure of the sample under magnifications of $50 \times$ and $500 \times$. As shown in the Figure 3, no holes and defects were observed within the microstructure.

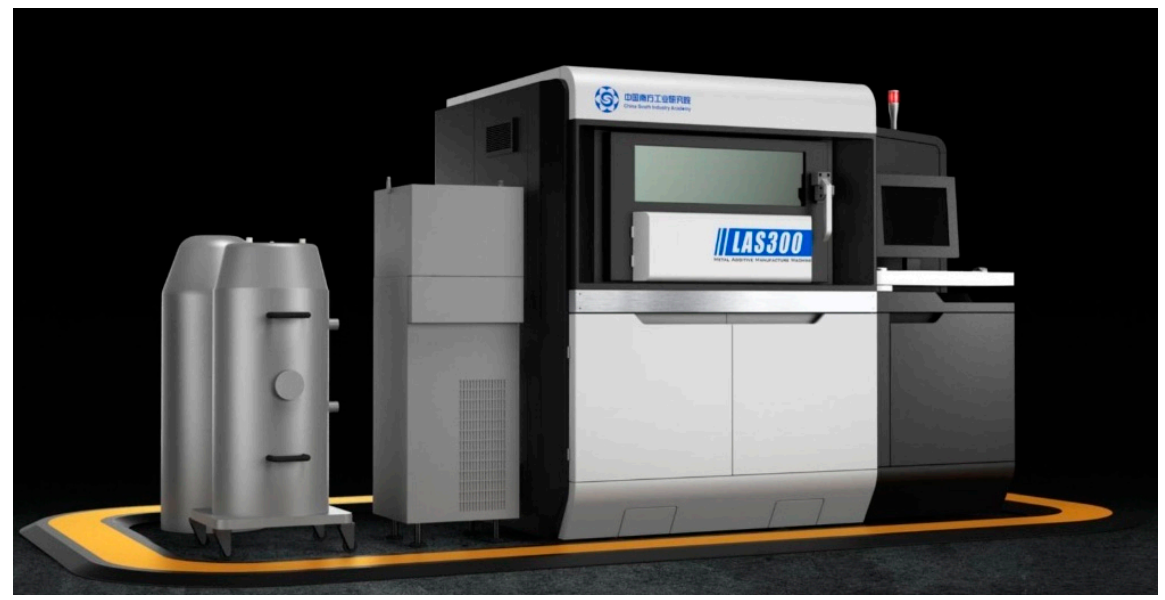

Figure 1. In-house selective laser melting equipment LAS300 with fiber laser.

Table 2. Selective laser melting process parameters.

\begin{tabular}{cc}
\hline Parameter & Values \\
\hline Laser Power & $340 \mathrm{~W}$ \\
Scan Speed & $1250 \mathrm{~mm} / \mathrm{s}$ \\
Layer Thickness & $60 \mu \mathrm{m}$ \\
\hline
\end{tabular}

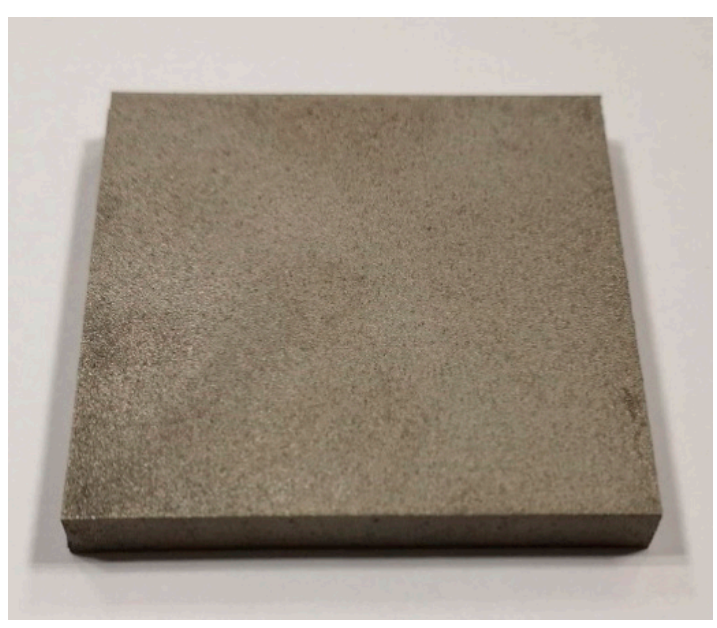

Figure 2. Additively manufactured TC-4 specimens. 


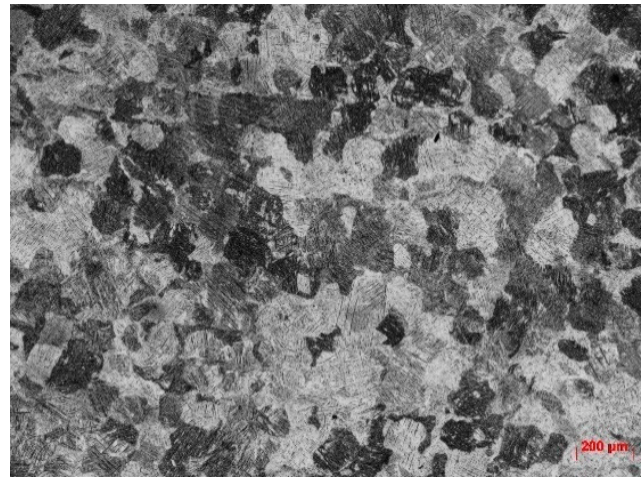

(a)

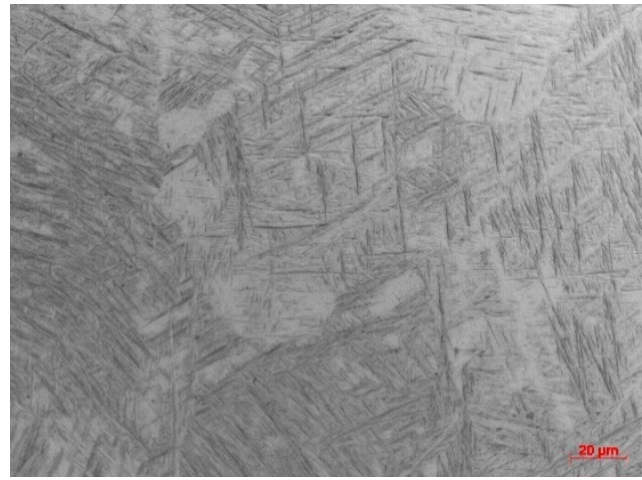

(b)

Figure 3. Microstructure of 3D-printed specimen: (a) $50 \times$; (b) $500 \times$.

\subsection{Test Method}

To study the compressive deformation behavior of the final prepared AM-TC-4 alloy and the difference in mechanical properties between this material and the TC-4 alloy prepared via the traditional manufacturing process, the AM-TC-4 alloy and TC-4 alloy specimens (diameter $\mathrm{D}=4 \mathrm{~mm}$ and thickness $\mathrm{L}=2 \mathrm{~mm}$ ) were prepared via the WEDM process. Among them, AM-TC-4 was sampled along the longitudinal printing direction (AM-P-TC-4) and transverse printing direction (AM-T-TC-4) to study the difference in the mechanical properties of AM-TC-4 in different printing directions; the sampling method is illustrated in Figure 4. Furthermore, the mechanical properties of the two materials under quasi-static and dynamic compressive deformation conditions were studied through the Material Universal Testing Machine (MUTM) and SHPB testing equipment (Figure 5). Specifically, the MUTM was used to compress the two materials at a constant strain rate and $286 \mathrm{~K}$. In the test, the crosshead speeds were $1.2 \mathrm{~mm} / \mathrm{min}$ and $12 \mathrm{~mm} / \mathrm{min}$. An extensometer was used to record the load-deformation relationship during the specimen deformation. The engineering stress-engineering strain and strain rate $\dot{\varepsilon}^{*}$ of the specimen were calculated using Equations (1)-(3):

$$
\begin{aligned}
\sigma_{e} & =\frac{f}{A_{S}} \\
\varepsilon_{e} & =\frac{e}{l} \\
\dot{\varepsilon}^{*} & =\frac{V}{l}
\end{aligned}
$$

where $\sigma_{e}$ is the engineering stress, $\varepsilon_{e}$ is the engineering strain, $A_{s}$ is the initial cross-sectional area of the specimen, and $l$ is the deformation. According to the assumption of constant volume, the $\sigma_{t}$ and $\varepsilon_{t}$ of the specimen were calculated using Equations (4) and (5).

$$
\begin{gathered}
\sigma_{t}=\sigma_{e}\left(1-\varepsilon_{e}\right) \\
\varepsilon_{t}=-\ln \left(1-\varepsilon_{e}\right)
\end{gathered}
$$

The SHPB equipment was used to study the dynamic compressive deformation behavior of materials under high-temperature and high-strain rate conditions. The selection of mechanical sample size reduces the influence of the inertia effect and stress imbalance on the test data as much as possible [19]. At the same time, in order to eliminate the influence of end face friction on the test results, $\mathrm{MoS}_{2}$ was used as lubricant in the experiment. Figure $5 \mathrm{~b}$ shows a schematic diagram of the SHPB test device, in which the rod material was $18 \mathrm{Ni}$ with $14.5 \mathrm{~mm}$ diameter, the bullet length was $400 \mathrm{~mm}$, and the lengths of the incident rod and the transmission rod were $1300 \mathrm{~mm}$; the strain gauges were installed in the middle of the incident rod and the transmission rod. The $\sigma_{t}, \varepsilon_{t}$, and the nominal 
strain rate $\dot{\varepsilon}$ of the material during the deformation process were calculated according to the strain signals obtained by the strain gauges on the incident rod and the transmission rod. The equations were as follows:

$$
\begin{gathered}
\sigma_{e}(t)=\frac{A_{b} E}{A_{s}} \varepsilon_{t r}(t) \\
\dot{\varepsilon}(t)=-\frac{2 C_{b}}{l_{s}} \varepsilon_{r e}(t) \\
\varepsilon_{e}(t)=\int_{0}^{t} \dot{\varepsilon}(t) d t
\end{gathered}
$$

where $A_{b}$ is the cross-sectional area of the rod; $l_{s}$ is the length of the specimen; $\varepsilon_{r e}$ and $\varepsilon_{t r}$ are the signals of the incident rod and the transmitted rod, respectively; and $E$ and $C_{b}$ are the elastic modulus and elastic wave velocity of the rod, respectively. According to Equations (4) and (5), the true stress $\sigma_{t}$ and true strain $\varepsilon_{t}$ corresponding to the specimen were calculated.

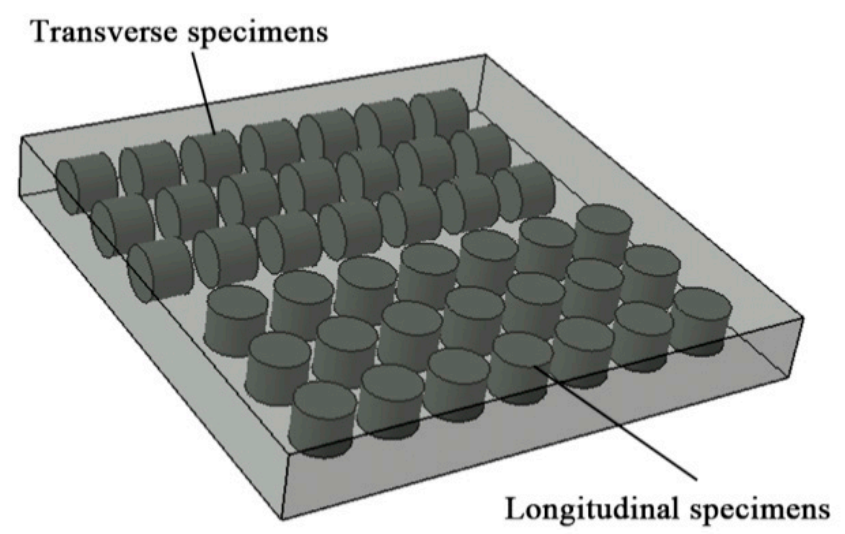

Figure 4. Sampling method of mechanical specimens.

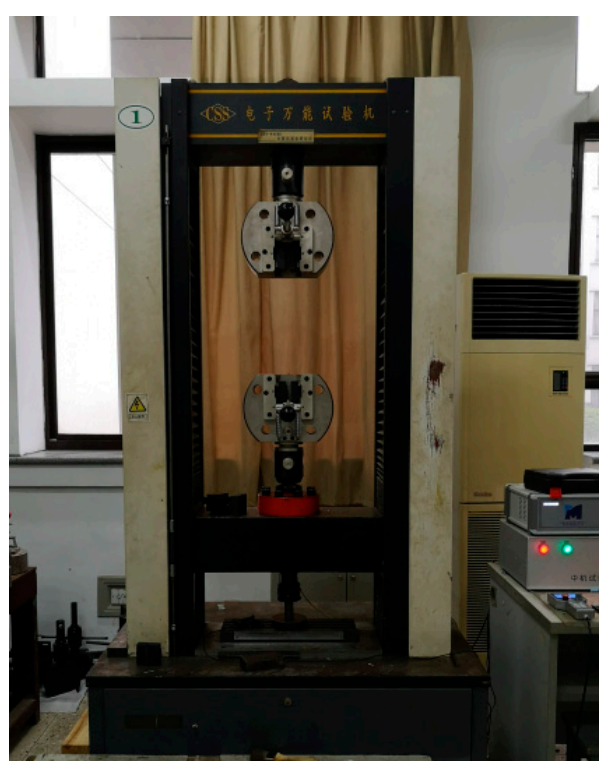

(a)

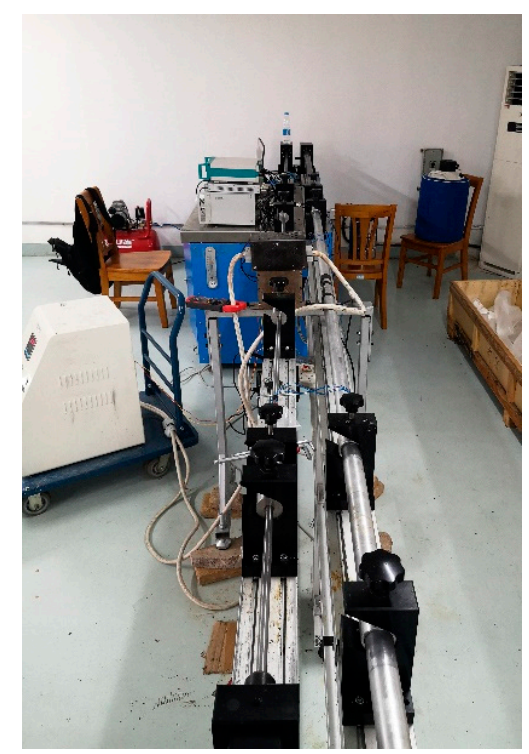

(b)

Figure 5. Mechanical test equipment: (a) MTS universal testing machine; (b) SHPB test equipment. 
In the SHPB test, it is very important to ensure the stress balance and constant strain rate deformation of materials. Figure $6 a, b$ were, respectively, the waveform diagram and the variation law of stress and strain rate with the strain of the 3D-printed TC-4 material under the deformation conditions of temperature $289 \mathrm{~K}$ and strain rate $1200 \mathrm{~s}^{-1}$. According to Figure $6 \mathrm{a}$, the rise time of the incident wave loading section in the experiment is $T=16.6 \mu \mathrm{s}$. The longitudinal wave depth of the TC-4 material was about $5130 \mathrm{~m} / \mathrm{s}$. when the loading force of the incident wave on the specimen reached the maximum, the stress wave repeatedly propagated in the specimen about 42 times. Therefore, it could be considered that the stress balance was reached everywhere in the specimen before plastic deformation.

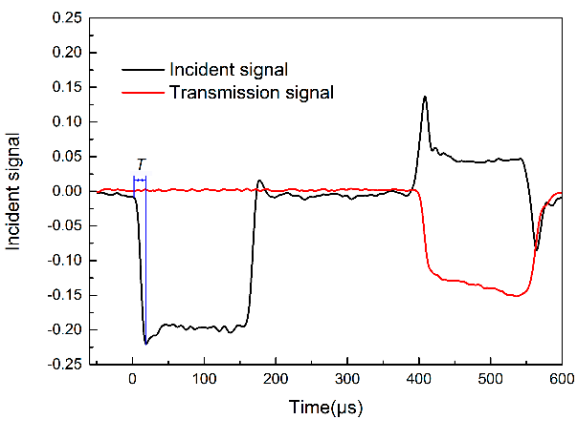

(a)

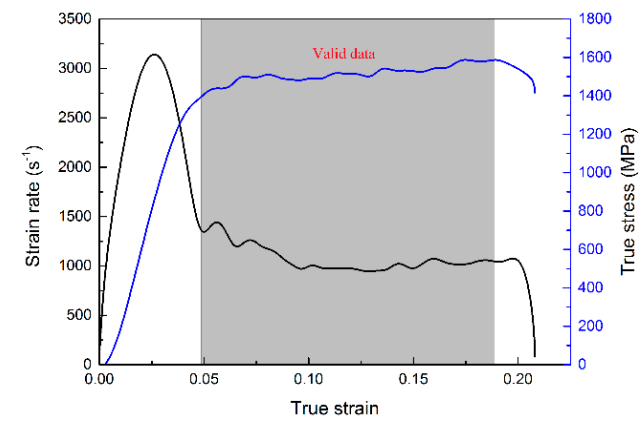

(b)

Figure 6. Stress balance and constant strain rate deformation (AM-P-TC-4, $289 \mathrm{~K}, 1200 \mathrm{~s}^{-1}$ ): (a) Waveform, (b) data selection.

In addition, as shown in Figure 6b, in the experiment, a constant deformation strain rate during plastic deformation was ensured. In the process of data processing, only the stress-strain relationship in the constant strain rate deformation range was selected for the next analysis and research, which also reduced the influence of the inertia effect on the accuracy of the test results.

\section{Test Results and Discussion}

\subsection{Stress-Strain Relationship}

Using MTS and SHPB test devices, the relationships between the equivalent plastic strain $\left(\varepsilon_{p}\right)$ and the equivalent stress $(\sigma)$ for TC-4 and AM-P-TC-4 specimens in the temperature range of $286-1073 \mathrm{~K}$ and strain rate of $0.1-4100 \mathrm{~s}^{-1}$ were obtained. With the stress value corresponding to the total strain of 0.05 as the apparent yield strength $\left(\sigma_{t c 5}\right)$ of the material [20,21], Figure 7 is the schematic diagram of yield point selection. Moreover, the stress-strain relationship of the AM-T-TC-4 specimen at room temperature and a strain rate of $0.1-4100 \mathrm{~s}^{-1}$ were obtained. The results are shown in Figure 8.

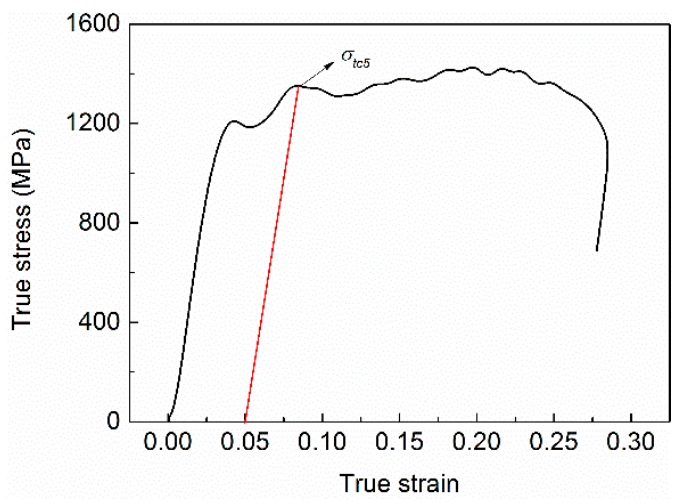

Figure 7. Selection of yield point. 


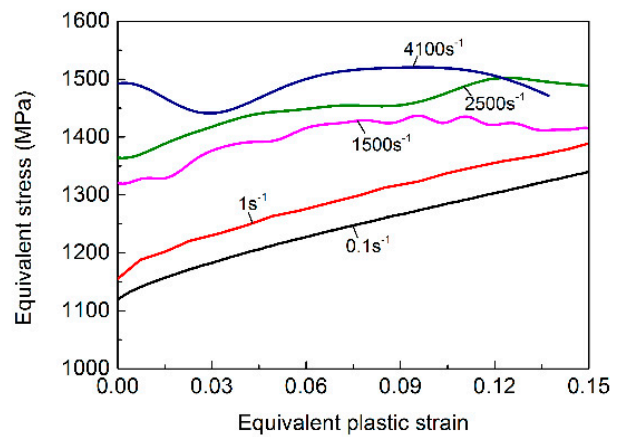

(a)

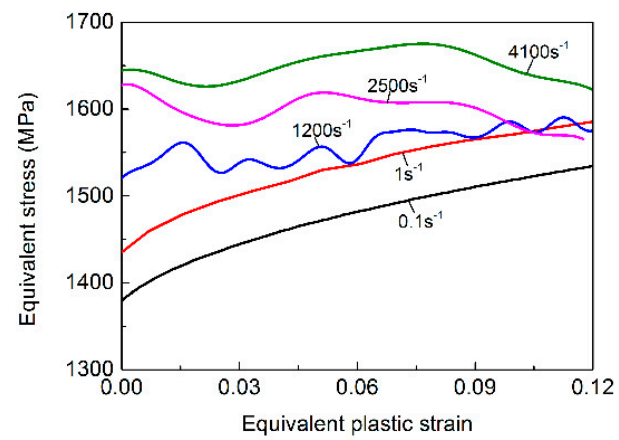

(c)

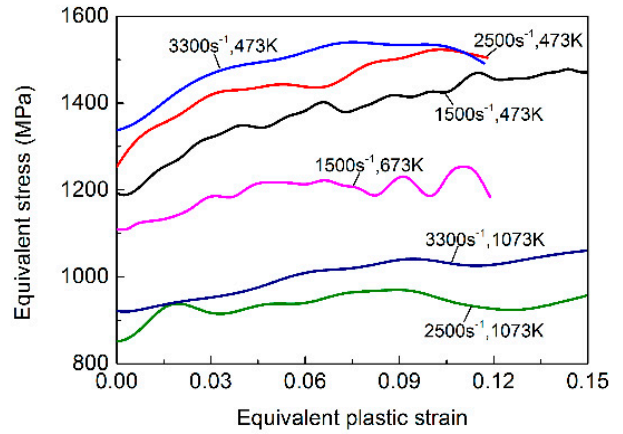

(b)

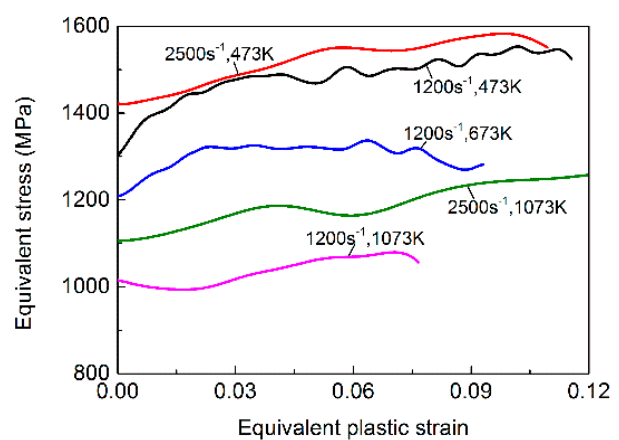

(d)

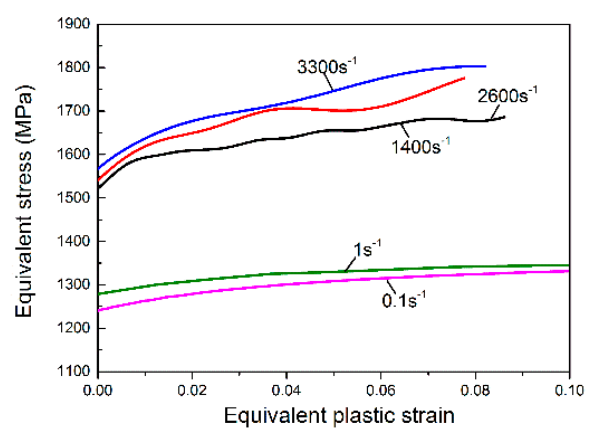

(e)

Figure 8. Stress-strain relationship of materials $(\mathbf{a}, \mathbf{c}, \mathbf{e})$ stress-strain curves of TC-4, AM-P-TC-4, and AM-T-TC-4 at $286 \mathrm{~K}$, respectively; (b,d) stress-strain curves of TC-4 and AM-P-TC-4 in hightemperature (473-1073 K) environment.

In addition, 50 TC-4 mechanical samples, 40 AM-P-TC4 samples, and 20 AM-T-TC4 samples were prepared, respectively, and three effective repeated tests were carried out for each deformation condition, and the test data within the constant strain rate range were averaged to ensure the reliability of the data. Figure $8 \mathrm{a}$,b show the $\varepsilon_{p}-\sigma$ relationship of the TC- 4 material prepared via the traditional process under normal-temperature $(286 \mathrm{~K})$ and high-temperature (473-1073 K) compressive deformation conditions. Figure 8c,b show the $\varepsilon_{p}-\sigma$ relationships of AM-P-TC-4 specimens under compressive deformation conditions at room temperature $(286 \mathrm{~K})$ and high temperature $(473-1073 \mathrm{~K})$, respectively. Figure 8e shows the $\varepsilon_{p}-\sigma$ relationship of the AM-T-TC-4 specimen under compressive deformation conditions at room temperature $(286 \mathrm{~K})$. According to the data in the figure, both materials exhibited certain work hardening and strain rate strengthening effects. The yield strength of the material increased with increasing strain rate, and the flow stress $\left(\varepsilon>\varepsilon_{p}\right)$ of the material increased with increasing plastic strain. Moreover, as the environmental temperature increased, the yield strength and flow stress of the material 
gradually decreased. In addition, under dynamic deformation, the heat generated by the material deformation could not be immediately transferred outward, so that the material temperature gradually increased with increasing deformation. Therefore, under high-strain rate deformation, the thermal softening effect reduced the slope of the material stress-strain curve. An additional analysis was performed on the influences of temperature and strain rate on the yield strength and fracture behavior of materials based on the experimental data in Figure 8.

\subsection{Effect of Strain Rate on Strength}

Figure 9a shows the difference in the yield strength of the 3D-printed TC-4 titanium alloy in the longitudinal and transverse printing directions and the effect of deformation strain rate on the yield strength. The analysis showed that the yield strength of the specimens (AM-T-TC-4) obtained perpendicular to the printing direction under quasistatic deformation conditions $\left(0.1-1 \mathrm{~s}^{-1}\right)$ was between 1240 and $1278 \mathrm{MPa}$, while the yield strength of the specimen (AM-P-TC-4) obtained along the printing direction was between 1379 and $1434 \mathrm{MPa}$, and the yield strength was $12 \%$ higher than that of AM-T-TC-4. However, as the deformation strain rate increased, the difference in the yield strength of the materials in the two directions gradually decreased; that is, under the condition of dynamic compressive deformation, the compression yield strength of 3D-printed TC- 4 in different directions tended to be consistent.

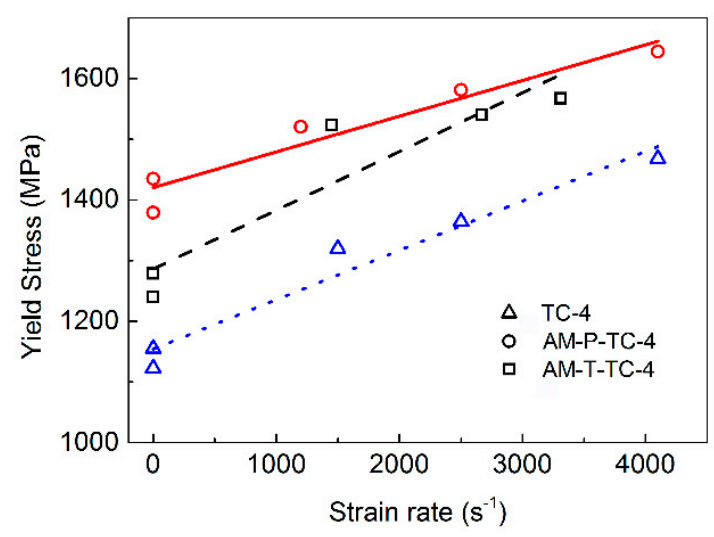

(a)

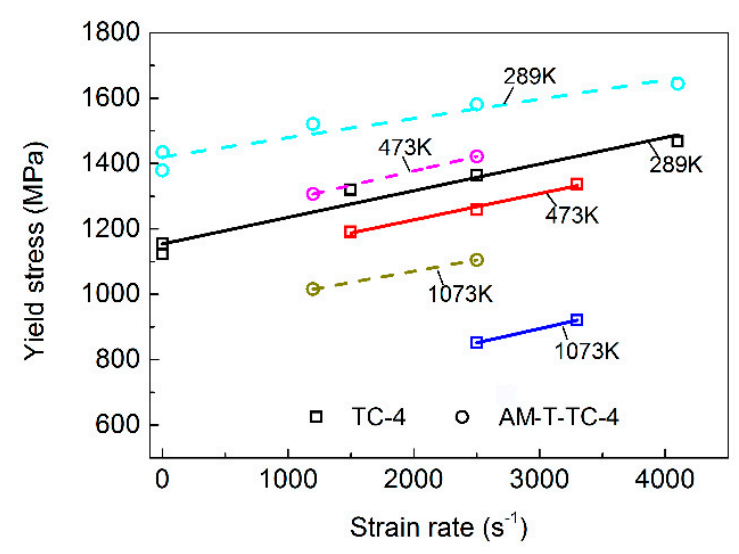

(b)

Figure 9. Effect of strain rate on the yield strength of materials: (a) Effect of strain rate on the yield strengths of TC-4, AM-P-TC-4, and AM-T-TC-4 at room temperature; (b) effect of strain rate on the yield strengths of TC-4 and AM-P-TC-4 at different temperatures. 
Figure $9 \mathrm{~b}$ shows the yield stress of TC-4 and AM-P-TC-4 materials at different strain rates under different initial environmental temperatures. From the data in the figure, the yield strength of the two materials in the strain rate range of $0.1-4000 \mathrm{~s}^{-1}$ increased linearly with increasing strain rate. In addition, under the same deformation conditions, the yield strength of AM-P-TC-4 was considerably higher than that of the traditional TC-4 material, but the strength of the traditional TC-4 material was more sensitive to the change in strain rate. At the initial environmental temperature of $289 \mathrm{~K}$, the strain rate increased from $0.1 \mathrm{~s}^{-1}$ to $4100 \mathrm{~s}^{-1}$, the yield strength of TC-4 increased from $1122.8 \mathrm{MPa}$ to $1492.2 \mathrm{MPa}$, and the gain was about $28.6 \%$. Under the same conditions, the yield strength of the AMP-TC-4 material increased from $1379.1 \mathrm{MPa}$ to $1644.2 \mathrm{MPa}$, with a gain of about $19.2 \%$. Moreover, under the conditions of a temperature of $289 \mathrm{~K}$ and a strain rate of $0.1 \mathrm{~s}^{-1}$, the yield strength of AM-P-TC-4 was 22.8\% higher than that of TC-4.

\subsection{Effect of Temperature on Strength}

Figure 10 shows the relationship between the yield stress of TC-4 and AM-TC-4 materials and the initial environmental temperature under different strain rates. In the temperature range of 289-1073 K, the yield strength of the two materials decreased linearly with increasing environmental temperature. Second, the high-temperature strength of AM-P-TC-4 was also greatly higher than that of TC-4. At a strain rate of $2500 \mathrm{~s}^{-1}$, the initial environmental temperature increased from $289 \mathrm{~K}$ to $1073 \mathrm{~K}$, and the yield strength of TC-4 material decreased from $1370.9 \mathrm{MPa}$ to $853.5 \mathrm{MPa}$, a decrease of about $37.7 \%$. Under the same conditions, the yield strength of the AM-P-TC-4 material decreased from $1557.9 \mathrm{MPa}$ to $1099.7 \mathrm{MPa}$, a decrease of about $29.4 \%$. It can be seen that the thermal sensitivity of AMP-TC-4 was lower than that of the TC-4 material; that is, AM-P-TC- 4 had higher strength and relatively better thermal stability at high temperatures.

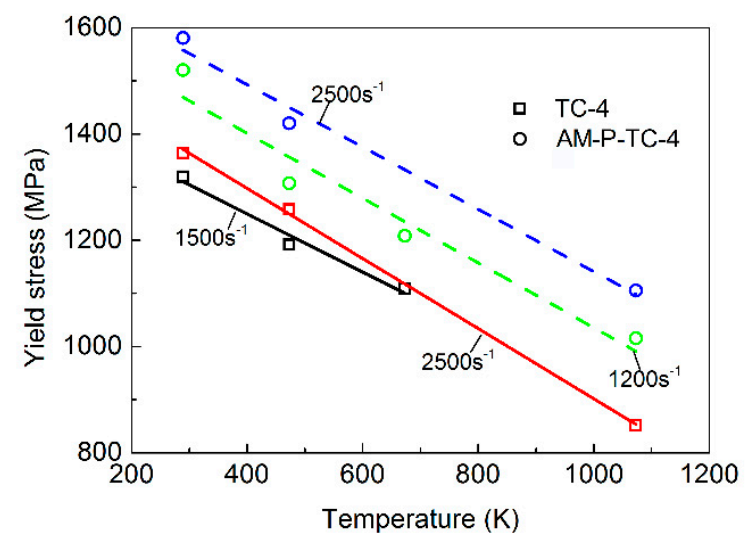

Figure 10. Relationship between material yield strength and initial environment temperature.

\subsection{Fracture Behavior}

The above sections focus on the effects of strain rate and temperature on the yield strengths of TC-4, AM-P-TC-4, and AM-T-TC-4 under dynamic compression conditions. The results showed the following: Compared with the traditional TC-4 material, the TC-4 titanium alloy material prepared by additive manufacturing had higher strength under the same deformation conditions. It was found in the experiment that when the material strain accumulated to a certain degree or the deformation strain rate was higher than a certain value, the titanium alloy material would undergo shear fracture during the deformation process. Studies have shown that the fracture behavior of titanium alloy materials is also affected by strain rate and temperature [22,23]. Titanium alloys are prone to adiabatic shear behavior under dynamic impact. As the strain rate increases, the material will produce more adiabatic shear bands and induce the localization of deformation, which makes the material more likely to fracture [23-25]. Therefore, we analyzed the fracture behaviors of TC-4, AM-P-TC-4, and AM-T-TC-4 under dynamic compressive deformation conditions. 
Figure 11a-c show the transmission voltage signals of TC-4, AM-P-TC-4, and AMT-TC-4 under impacts of different strain rates, obtained by SHPB test. According to Equation (6), the transmission voltage signal is positively correlated with the deformation stress of the material. When the material breaks during the stress wave loading process, stress unloading occurs inside the material, which causes the transmission voltage signal to drop sharply in the first loading cycle. As the broken material is further compacted, the subsequent voltage signal rises again. The first inflection point at which the voltage signal appears to fall is taken as the time $t_{f}$ when the material breaks during the deformation process. The strain $\varepsilon_{f}$ when the material breaks can be roughly estimated by Equation (9).

$$
\varepsilon_{f} \cong \int_{0}^{t_{f}} \dot{\varepsilon} d t
$$

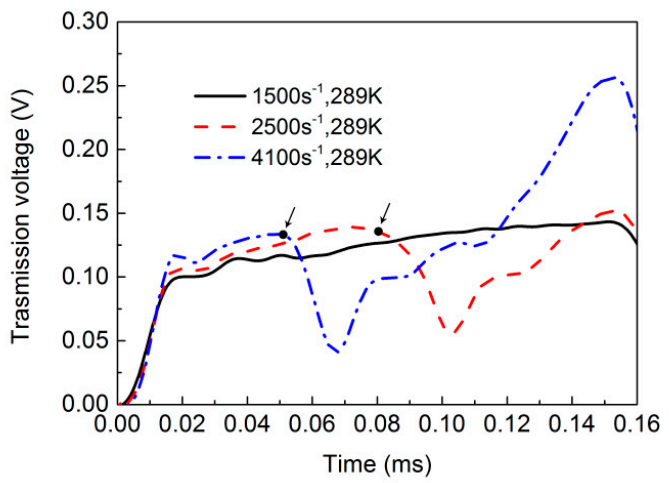

(a)

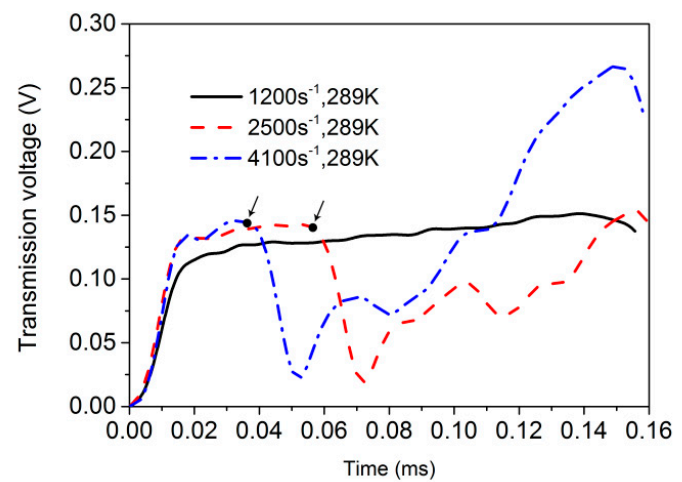

(b)

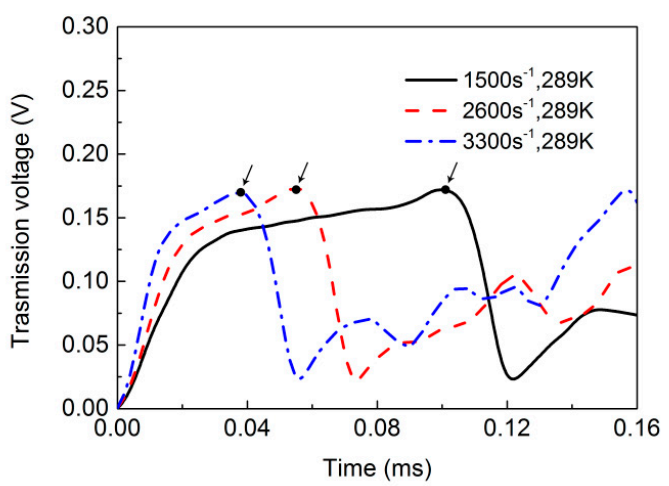

(c)

Figure 11. Transmission voltage signal of materials under dynamic compression conditions: (a) TC-4, (b) AM-P-TC-4, and (c) AM-T-TC-4. 
Figure 12 shows the corresponding relationship between the maximum strain of the three materials TC-4, AM-P-TC-4, and AM-T-TC-4 (calculated according to Equation (9)) in the first loading cycle under normal temperature conditions and the deformation strain rate, and the deformation state of the corresponding specimen. Compared with the traditional TC-4 material, the TC-4 titanium alloy material prepared via the 3D-printing process was more prone to fracture due to adiabatic shear under the same deformation conditions. In addition, the maximum fracture strain of the material in different printing directions was also different. Under a strain rate of $2500 \mathrm{~s}^{-1}$, the fracture strain of the traditional TC-4 material reached 0.2175, while the fracture strains of AM-P-TC-4 and AM-T-TC-4 were 0.1425 and 0.1316 , respectively, which were $52.6 \%$ and $65.3 \%$ lower than that of the traditional TC-4 material, respectively.

Figure 13 shows the effect of temperature on the fracture behaviors of TC-4 and AM-P-TC-4. Under a strain rate of $2500 \mathrm{~s}^{-1}$, the adiabatic shear fracture behavior of the TC-4 material was suppressed with increasing initial environmental temperature, and its fracture strain gradually increased. When the initial environmental temperature increased to $673 \mathrm{~K}$, the fracture phenomenon of the TC-4 material in the first loading cycle disappeared. However, the fracture behavior of the AM-P-TC-4 material prepared via additive manufacturing was not significantly improved with an increase in the initial environmental temperature.

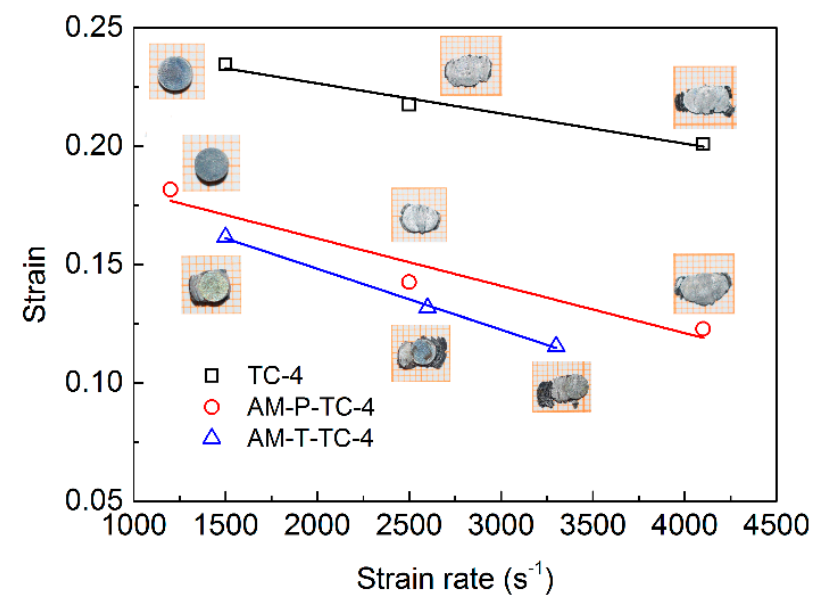

Figure 12. Effect of strain rate on material fracture behavior.

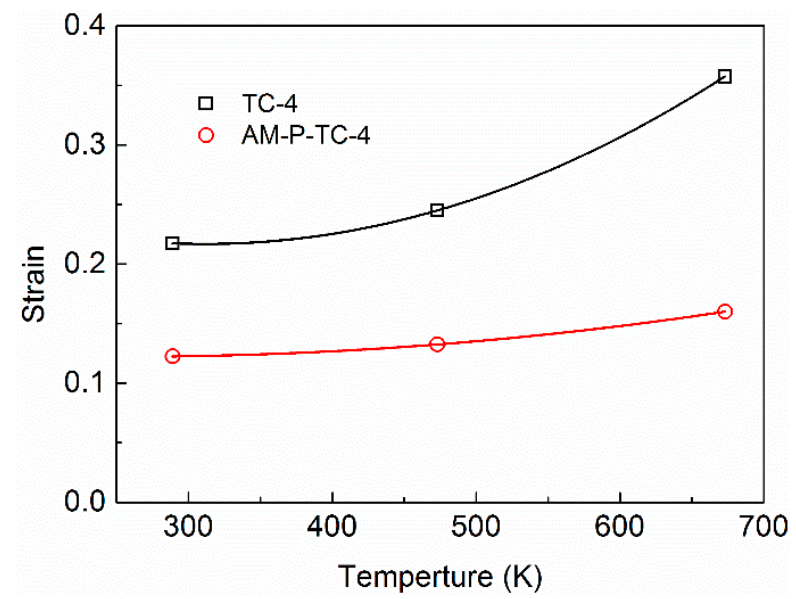

Figure 13. Effect of temperature on material fracture behavior. 


\subsection{Constitutive Relations}

The above sections describe the plastic deformation and fracture behavior of TC- 4 and 3D-printed TC-4 titanium alloy in the temperature range of $289-873 \mathrm{~K}$ and strain rate of $0.1-4100 \mathrm{~s}^{-1}$. The preliminary results showed that the TC-4 material prepared by additive manufacturing had higher strength than the traditionally prepared TC-4 material. However, TC-4 materials prepared by additive manufacturing processes under dynamic deformation conditions are more prone to the localization of deformation caused by adiabatic shear.

In 1983, Johnson and Cook [26] proposed a constitutive model (J-C constitutive) suitable for describing the stress-strain relationship of metallic materials under hightemperature, high-strain rate, and large deformation conditions. The model comprehensively considers the impacts of strain rate effects and temperature on flow stress. The model equation is as follows:

$$
\sigma=\left(A+B \varepsilon_{p}^{n}\right)\left(1+C \ln \varepsilon^{*}\right)\left(1-T^{* m}\right)
$$

where $A, B, n, C$, and $m$ are the material constitutive parameters to be determined; $\dot{\varepsilon}^{*}=\frac{\dot{\varepsilon}}{\dot{\varepsilon}_{0}}$ ( $\dot{\varepsilon}_{0}$ is the reference strain rate); and $T^{*}=\frac{\left(T-T_{r}\right)}{\left(T-T_{m}\right)}$, where $T_{r}$ is the reference temperature, and $T_{m}$ is the material melting point.

Under the reference temperature and the reference strain rate, Equation (11) is used by the J-C constitutive to describe the relationship between the yield strength of the material and the strain rate; that is, when the plastic strain $\varepsilon_{p}=0$, Equation (10) can be simplified as

$$
\sigma_{0.2}=A\left(1+C \ln \dot{\varepsilon}^{*}\right)
$$

However, within the strain rate range of $0.01-4100 \mathrm{~s}^{-1}$, the strain rate strengthening behaviors of the TC-4 and AM-P-TC-4 materials used in this study were nonlinear (Figure 14), and the J-C model apparently could not effectively describe the behavior of the materials. Huh and Kang [27] replaced the linear form of the J-C constitutive with a one-variable quadratic form (Equation (12)) considering strain rate-related terms, as shown in Figure 14. Compared with the J-C constitutive, the strain rate-related items proposed by Huh and Kang showed a better correlation with the test data. Therefore, the second term in the J-C constitutive was modified. Equation (12) was used to describe the strain rate strengthening behavior of the two materials, and the modified constitutive form is shown in Equation (13).

$$
\begin{gathered}
\sigma_{0.2}=A\left(1+C_{1} \ln \dot{\varepsilon}^{*}+C_{2} \ln \dot{\varepsilon}^{* 2}\right) \\
\sigma=\left(A+B \varepsilon_{p}^{n}\right)\left(1+C_{1} \ln \dot{\varepsilon}^{*}+C_{2} \ln \dot{\varepsilon}^{* 2}\right)\left(1-T^{* m}\right)
\end{gathered}
$$

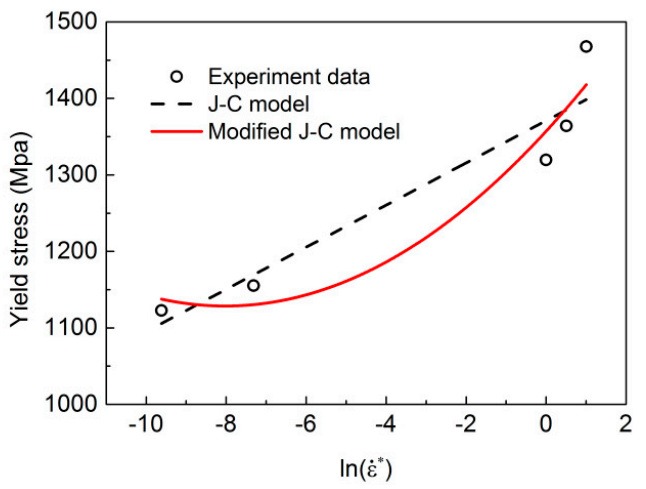

(a)

Figure 14. Cont. 


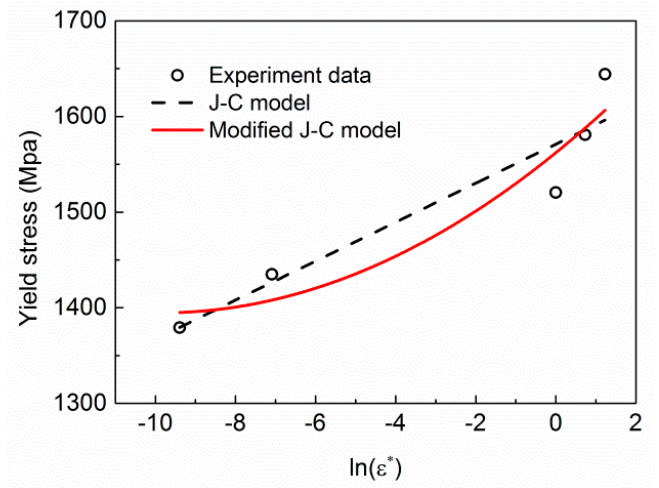

(b)

Figure 14. Strain rate strengthening behaviors of (a) TC-4 and (b) AM-P-TC-4.

The stress-plastic strain data at the reference temperature $T_{r}$ and the reference strain rate $\dot{\varepsilon}_{0}$ were used to determine the parameters $A$ and $B$. The functional relationship of $\sigma_{0.2}-\ln \left(\dot{\varepsilon}^{*}\right)$ at different reference temperatures and strain rates was used to determine $\mathrm{C}_{1}$ and $\mathrm{C}_{2}$. The function relationship of $\ln \left(1-\frac{\sigma_{0.2}}{A}\right)-\ln \left(T^{*}\right)$ at a reference strain rate and different environmental temperatures was used to determine the parameter $m$. Finally, the stress-plastic strain data at different temperatures and different strain rates obtained in the experiment were used to conduct the least-squares optimization for the obtained initial values of the material parameters, and the final constitutive parameters were obtained (Table 3).

Considering the temperature rise of metallic materials due to adiabatic deformation under dynamic conditions [28], the constitutive parameters in Table 3 were used to predict the equivalent stress-equivalent plastic strain data of the two materials at different initial and different strain rates, and the results were compared with experimental data. Figure 15 shows that the modified J-C constitutive model constructed in this paper could effectively predict the mechanical responses of TC-4 and AM-P-TC-4 under high-temperature and high-strain rate deformation conditions, and the experimental data were consistent with the predicted data.

Table 3. Constitutive parameters.

\begin{tabular}{cccc}
\hline Description & Notations & TC-4 & AM-P-TC-4 \\
\cline { 3 - 4 } & & 4.459 & 4.120 \\
Density & $\rho\left(\mathrm{g} / \mathrm{cm}^{3}\right)$ & 1357.2 & 1480.3 \\
Yield stress constant & $A(\mathrm{Mpa})$ & 303.15 & 480.3 \\
Strain hardening constant & $B(\mathrm{Mpa})$ & 0.686 & 0.465 \\
- & $n$ & 0.0519 & 0.0217 \\
Strain rate hardening constant & $C_{1}$ & 0.0116 & 0.018 \\
Strain rate hardening constant & $C_{2}$ & 1.17 & 1.15 \\
Thermal softening constant & $m$ & 1500 & 1200 \\
Reference strain rate & $\dot{\varepsilon}_{0}\left(\mathrm{~s}^{-1}\right)$ & 2110 & 2110 \\
Melting temperature & $T_{m}(\mathrm{~K})$ & 289 & 289 \\
Reference temperature & $T_{r}(\mathrm{~K})$ & &
\end{tabular}




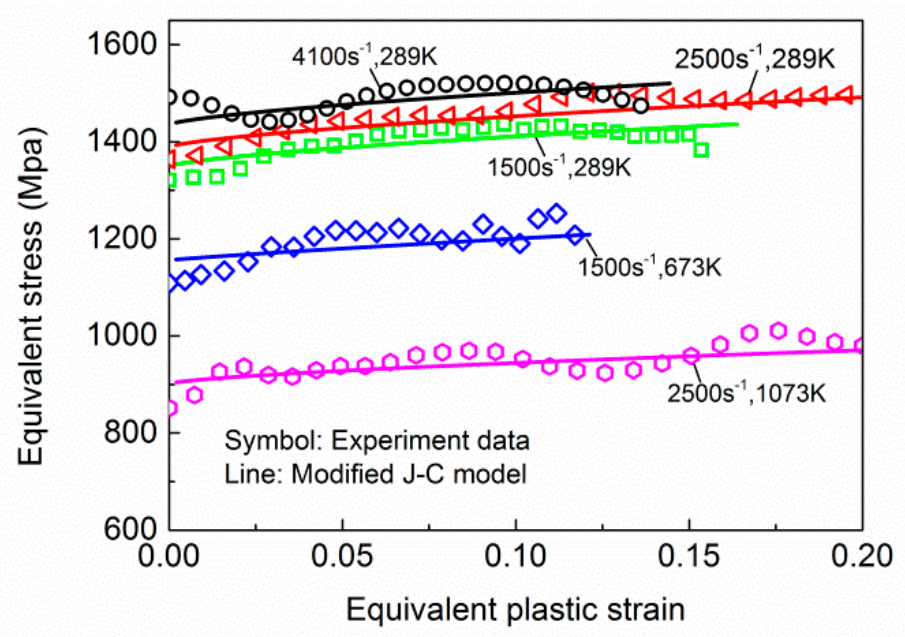

(a)

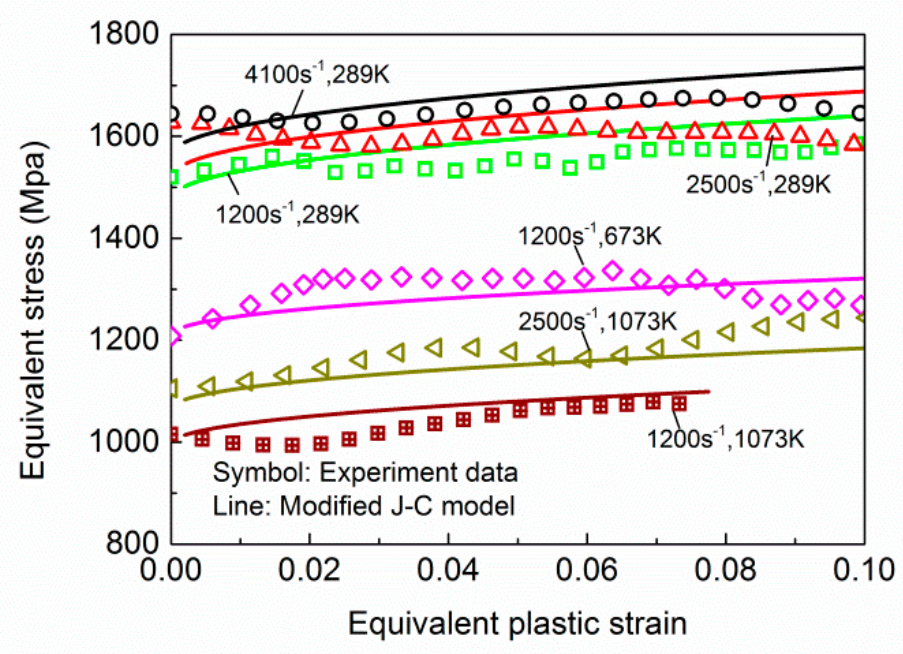

(b)

Figure 15. Accuracy validation of modified J-C constitutive: (a) TC-4; (b) AM-P-TC-4.

\subsection{Plastic Deformation Behavior under Extreme Conditions}

The previous sections have described the use of the SHPB test to study the temperature (289-1073 K) and strain rate $\left(0.1-4100 \mathrm{~s}^{-1}\right)$ to systematically analyze the plastic deformation behavior of 3D-printed TC-4 titanium alloy material, and the results have been compared with the traditionally prepared TC-4 titanium alloy. To explore the plastic deformation behavior of the 3D-printed TC-4 material under higher-strain rate conditions, the shapedcharge warhead was used to study the plastic deformation behavior of the 3D-printed TC-4 under more extreme deformation conditions and the difference between this material and the traditional TC-4 materials. The TC-4 and AM-P-TC-4 were separately used as liner materials in the shaped-charge warheads, and the pressure generated by the explosive detonation was up to $30 \mathrm{GPa}$; the pressure drives the liner materials to collapse and converge inward, thereby forming a high-speed metal jet that moves forward. The deformation strain rate of the material in the whole process was as high as $10^{5} \mathrm{~s}^{-1}$. Additionally, X-ray photography was used to take images of the jet shape at a specific time after detonation, so that comparative study could be performed on the shaping forms of the rod-shaped jets of TC-4 and AM-P-TC-4 liner materials under the detonation-driving action. Figure 16a shows a schematic diagram of the structure of the shaped-charge warhead used in this study, and Figure 16b shows the images of the shaped-charge warhead prepared with TC- 4 
and AM-P-TC-4 titanium alloy as the liner material. For the shaped-charge warhead and $X$-ray photography experiment, more descriptions can be found in reference [29].

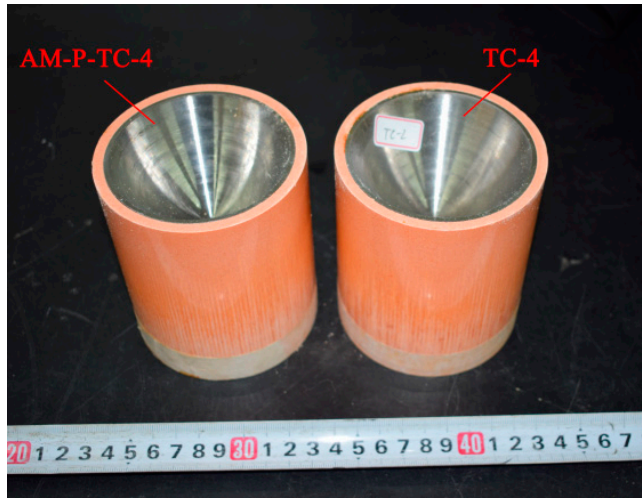

(a)

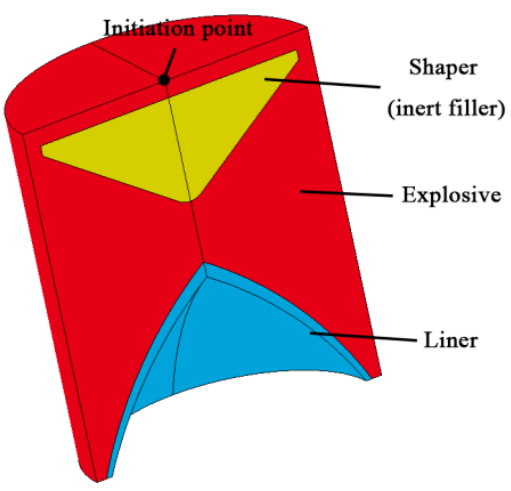

(b)

Figure 16. Shaped-charge warheads: (a) TC-4 and AM-P-TC-4 warheads; (b) structure diagram of shaped-charge warhead.

Table 4 presents the shaping forms, obtained by X-ray photography, of the jets of TC-4 and AM-P-TC-4 liner materials under the driving action of detonation pressure. According to the movement distance of the jet between the two images, the head and tail velocities of the TC-4 jet were $8383 \mathrm{~m} / \mathrm{s}$ and $2525 \mathrm{~m} / \mathrm{s}$, respectively. The head and tail velocities of the AM-P-TC- 4 jet were $8185 \mathrm{~m} / \mathrm{s}$ and $2438 \mathrm{~m} / \mathrm{s}$, respectively. Furthermore, the titanium alloy liner collapsed inward under the driving action of high pressure, and converged on the axis, thus forming a high-speed long-rod-shaped jet. However, due to the large velocity difference between the head and tail of the jet, the jet would break during subsequent flights. Compared with the TC-4 material, the jet head formed by the AM-P-TC-4 liner material possessed worse cohesiveness and showed significant expansion and spreading trends during the stretching and forming process.

The results of mechanical tests show that the fracture strain of AM-P-TC-4 material was obviously less than that of TC-4 under the same deformation conditions. At the same time, the increase of ambient temperature did not lead to a significant increase of fracture strain of AM-P-TC-4 material. It led to more severe fracture and breaking behavior of AM-P-TC-4 jet driven by detonation compared to TC-4.

Table 4. Comparison of shape-forming of TC-4 and AM-TC-4 jets.

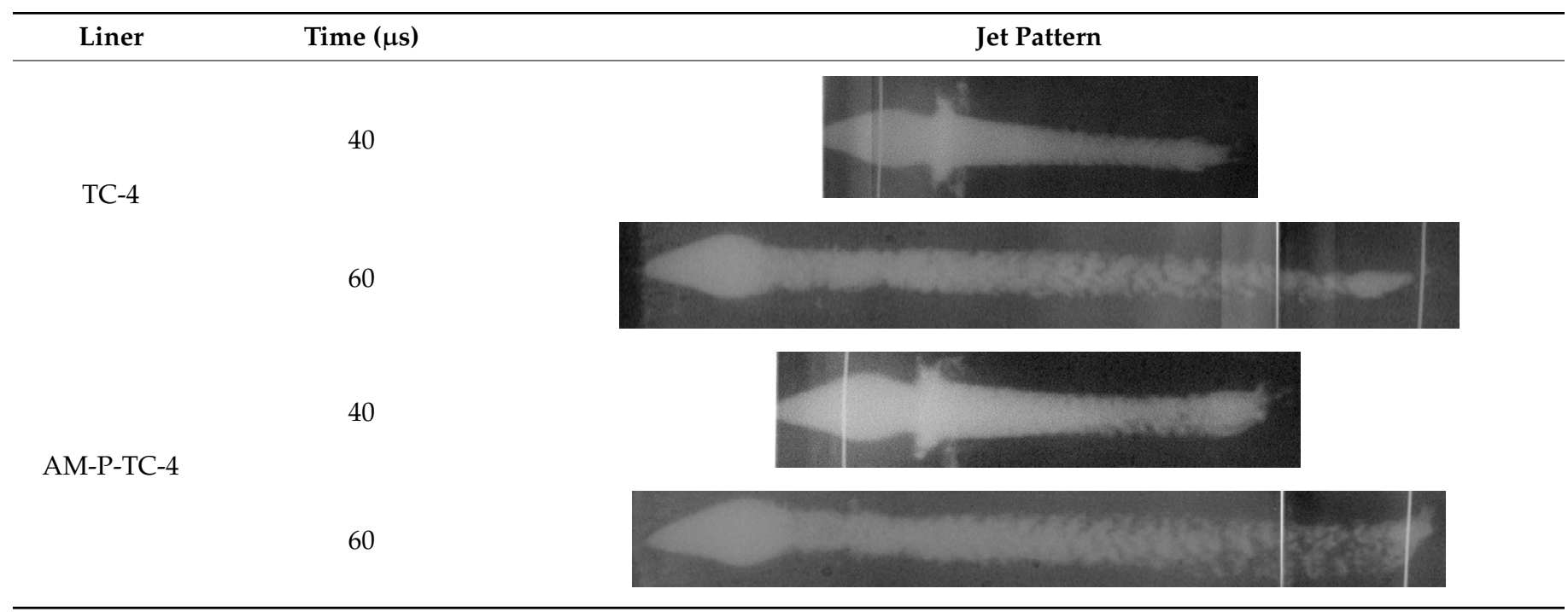




\section{Conclusions}

In this study, the Ti6Al4V alloy was prepared based on the selective laser melting 3Dprinting process, and the MTS material universal testing machine and SHPB test equipment were used to study the mechanical properties of 3D-printed Ti6Al4V alloy and traditionally prepared Ti6Al4V alloy (TC-4) under high-temperature (289-1073 K) and high-strain rate (0.1-4100 s $\left.{ }^{-1}\right)$ compressive deformation conditions. The mechanical properties of the 3D-printed TC-4 alloy (AM-P-TC-4 and AM-T-TC-4) in different printing directions were compared and investigated. The effects of temperature and strain rate on the material strength and fracture behavior were analyzed, and a modified J-C constitutive model of AM-P-TC-4 and TC-4 was established. Finally, the plastic deformation behavior of AM-PTC-4 and TC-4 materials driven by detonation was studied through a shaped-charge jet warhead. The research results indicate the following:

1. The TC-4 alloy prepared via 3D printing had higher strength than the traditional TC-4 alloy. However, the 3D-printed TC-4 alloy was more prone to adiabatic shear fracture under dynamic compressive deformation conditions.

2. The TC-4 alloy prepared via 3D-printing technology exhibited certain differences in material properties in different printing directions. The material sampled longitudinally along the printing direction under static conditions had higher strength than the material sampled transversely, but the difference was smaller under dynamic deformation conditions.

3. The established modified J-C constitutive model could effectively describe the stressstrain relationship of the AM-P-TC-4 material under dynamic compressive deformation.

Author Contributions: Conceptualization, B.P. and W.L.; methodology, B.P.; software, B.P.; validation, B.P., Q.Z. and X.W.; writing-review and editing, B.P. and Y.Z.; funding acquisition, W.L. All authors have read and agreed to the published version of the manuscript.

Funding: This research received no external funding.

Data Availability Statement: Not applicable.

Conflicts of Interest: The authors declare no conflict of interest.

\section{References}

1. Brewer, W.D.; Bird, R.K.; Wallace, T.A. Titanium alloys and processing for high speed aircraft. Mater. Sci. Eng. A Struct. 1998, A243, 299-304. [CrossRef]

2. Poondla, N.; Srivatsan, T.; Patnaik, A.; Petraroli, M. A study of the microstructure and hardness of two titanium alloys: Commercially pure and Ti-6Al-4V. J. Alloys Compd. 2009, 486, 162-167. [CrossRef]

3. Ngo, D.T.; Kashani, A.; Imbalzano, G.; Nguyen, K.T.Q.; Hui, D. Additive manufacturing (3D printing): A review of materials, methods, applications and challenges. Compos. Part B 2018, 143, 172-196. [CrossRef]

4. Kotkunde, N.; Deole, A.D.; Gupta, A.K.; Singh, S.K. Comparative study of constitutive modeling for Ti-6Al-4V alloy at low strain rates and elevated temperatures. Mater. Des. 2014, 55, 999-1005. [CrossRef]

5. Sun, J.; Guo, Y.B. Material flow stress and failure in multiscale machining titanium alloy Ti-6Al-4V. Int. J. Adv. Manuf. Technol. 2008, 41, 651-659. [CrossRef]

6. Sima, M.; Özel, T. Modified material constitutive models for serrated chip formation Simulations and experimental validation in machining of titanium alloy Ti-6Al-4V. Int. J. Mach. Tools Manuf. 2010, 55, 943-960. [CrossRef]

7. Lee, W.-S.; Lin, C.-F. Plastic deformation and fracture behaviour of Ti-6Al-4V alloy loaded with high strain rate under various temperatures. Mater. Sci. Eng. A 1998, 241, 48-59. [CrossRef]

8. Song, P.; Li, W.B.; Zheng, Y.; Guan, Z.W.; Wang, X.M.; Xu, W.X.; Ge, P. The constitutive behavior of Ti-5Al-3V-2Cr-2Fe under high-velocity impact: Experimental, modeling, and validation. J. Alloys Compd. 2019, 811, 1-12. [CrossRef]

9. Sterling, A.; Shamsaei, N.; Torries, B.; Thompson, S.M. Fatigue behavior of additively manufactured TC4. Procedia Eng. 2015, 133, 576-589. [CrossRef]

10. Galarrag, H.; Warren, R.J.; Lados, D.A.; Dehoff, R.R.; Kirka, M.M.; Nandwana, P. Effects of heat treatments on microstructure and properties of TC4 ELI alloy fabricated by electron beam melting (EBM). Mater. Sci. Eng. A Struct. 2017, 685, 417-428. [CrossRef]

11. Li, W.; Liou, F.; Newkirk, J.; Taminger, K.M.B.; Seufzer, W.J. Ti6Al4V/SS316 multi-metallic structure fabricated by laser 3D printing and thermodynamic modeling prediction. Int. J. Adv. Manuf. Technol. 2017, 92, 4511-4523. [CrossRef]

12. Refael, F.; Daniel, R.; Amnon, S. Dynamic Mechanical Behavior of Additively Manufactured Ti6AI4V with Controlled Voids. J. Appl. Mech. 2015, 82, 041004. 
13. Dutta, B.; Froes, F.H. The additive manufacturing (AM) of titanium alloys. Titan. Powder Metall. 2015, 447-468. [CrossRef]

14. Fadida, R.; Shirizly, A.; Rittel, D. Dynamic Tensile Response of Additively Manufactured Ti6Al4V with Embedded Spherical Pores. J. Appl. Mech. 2018, 85, 041004. [CrossRef]

15. Fiaz, H.S.; Settle, C.R.; Hoshin, K. Metal additive manufacturing for microelectromechanical systems: Titanium alloy (Ti-6Al-4V)based nanopositioning flexure fabricated by electron beam melting. Sens. Actuators A Phys. 2016, 249, 284-293. [CrossRef]

16. Xiao, L.; Song, W.; Wang, C.; Liu, H.; Tang, H.; Wang, J. Mechanical behavior of open-cell rhombic dodecahedron Ti-6Al-4V lattice structure. Mater. Sci. Eng. A Struct. 2015, 640, 375-384. [CrossRef]

17. Xiao, L.; Song, W.; Wang, C.; Tang, H.; Liu, N.; Wang, J. Yield behavior of open-cell rhombic dodecahedron Ti-6Al-4V lattice at elevated temperatures. Int. J. Mech. Sci. 2016, 115-116, 310-317. [CrossRef]

18. Xiao, L.; Song, W.; Wang, C.; Tang, H.; Fan, Q.; Liu, N.; Wang, J. Mechanical properties of open-cell rhombic dodecahedron titanium alloy lattice structure manufactured using electron beam melting under dynamic loading. Int. J. Impact Eng. 2017, 100, 75-89. [CrossRef]

19. Nemat-Nasser, S.; Isaacs, J.B.; Starrett, J.E. Hopkinson techniques for dynamic recovery experiments. Proc. R. Soc. Lond. A 1991, $435,371-391$.

20. Zhang, X.-M.; Li, H.-J.; Li, H.-Z.; Gao, H.; Gao, Z.-G.; Liu, Y.; Liu, B. Dynamic property evaluation of aluminum alloy 2519A by split Hopkinson pressure bar. Trans. Nonferrous Met. Soc. China 2008, 18, 1-5. [CrossRef]

21. Lee, W.-S.; Tang, Z.-C. Relationship between mechanical properties and microstructural response of 6061-T6 aluminum alloy impacted at elevated temperatures. Mater. Des. 2014, 58, 116-124. [CrossRef]

22. Qiang, L.; Yongbo, X.; Bassim, M.N. Dynamic mechanical properties in relation to adiabatic shear band formation in titanium alloy-Ti17. Mater. Sci. Eng. A Struct. 2003, 358, 128-133. [CrossRef]

23. Liu, J.; Fan, Q.; Cai, H.; Wang, F. Underlying mechanism of periodical adiabatic shear bands generated in Ti-6Al-4V target by projectile impact. Mater. Des. 2015, 87, 231-237. [CrossRef]

24. Me-Bar, Y.; Rosenberg, Z. On the correlation between the ballistic behavior and dynamic properties of titanium-alloy plates. Int. J. Impact Eng. 1997, 19, 311-318. [CrossRef]

25. Holt, W.H.; Mock, W.; Soper, W.G.; Coffey, C.S.; Ramachandran, V.; Armstrong, R.W. Reverse-ballistic impact study of shear plug formation and displacement in Ti6Al4V alloy. J. Appl. Phys. 1993, 73, 3753-3759. [CrossRef]

26. Johnson, G.R.; Cook, W.H. A Constitutive Model and Data for Metals Subjected to Large Strains, High Strain Rates and High Temperatures. In Proceedings of the 7th International Symposium on Ballistic, The Hague, The Netherlands, 19-21 April 1983; pp. 541-547.

27. Huh, H.; Kang, W.J.; Han, S.S. A Tension Split Hopkinson Bar for Investigating the Dynamic Behavior of Sheet Metals. Exp. Mech. 2002, 42, 8-17. [CrossRef]

28. Rajeev, K.; Sia, N.N. Determination of temperature rise during high strain rate deformation. Mech. Mater. 1998, $24,1-12$.

29. Song, P.; Li, W.-B.; Zheng, Y.; Song, J.-P.; Jiang, X.-C.; Yan, B.-Y. Study on Plastic Deformation Behavior of Mo-10Ta under Ultra-High Strain Rate. Metals 2020, 10, 1153. [CrossRef] 